\title{
Accessibility: Distribution across diverse populations
}

\author{
Kristin Carlson \\ University of Minnesota \\ Andrew Owen \\ University of Minnesota
}

\begin{abstract}
High-resolution data are used to evaluate the distribution of job accessibility among workers at the national, state, regional, and urban scales. Here, accessibility refers to the ease of reaching valuable destinations by transit and driving time. Annually updated accessibility datasets produced by the National Accessibility Evaluation are paired with Census data to tie accessibility, jobs, and worker information at the block level. Minnesota is selected as a case study for analyzing accessibility and drawing findings from the spatial datasets. The average accessibility by worker age, monthly earnings, educational attainment, race, and sex are calculated using data for the weekday morning commute by automobile and transit. The greatest variation in average accessibility among demographic groups is found for worker race. Based on home location, non-White workers systematically experience far higher accessibility to jobs by both automobile and transit than White workers as a percent difference from the population average. The finding holds at the national, state, and regional geographies. Additional findings are presented for each demographic group. The analyses presented here can be applied to other states and regions to; identify where accessibility is distributed most and least equitably, and to guide policy decisions for equitable job, housing, and transportation investments.
\end{abstract}

Keywords: Minimobility; Transit; Operational Efficiency; Electric Vehicles
Article History:

Received: January 26, 2021

Revised: May 5, 2021

Accepted: May 6, 2021

Available online: De-

cember 28,2021

\section{Introduction}

Accessibility is a multi-faceted measure of the costs of travel (time, money, etc.) and the benefits (opportunities, services, etc.). By accounting for both transportation systems and land use, accessibility captures some of reasons why we travel. Accessibility varies across a region-meaning different people have varying degrees of accessibility. Collectively, some groups of people may experience high or low levels of accessibility as a manifestation of regional land use policies and transportation options. The difference in average accessibility levels between groups may inform equitable planning of land use and transportation systems. This paper shows how existing high-resolution datasets can be analyzed to offer greater detail on accessibility trends among various socio-economic and demographic groups.

Copyright 2021 Kristin Carlson and Andrew Owen.

doi: $10.5198 /$ jtlu.2021.1963

ISSN: 1938-7849| Licensed under the Creative Commons Attribution - NonCommercial License 4.0.

The Journal of Transport and Land Use is the official journal of the World Society for Transport and Land Use (WSTLUR) and is published and sponsored by the University of Minnesota Center for Transportation Studies. 
The analysis is repeated at four geographic scales to demonstrate how these trends vary by aggregation level.

Block-level, cumulative job accessibility data is available for the United States through the National Accessibility Evaluation project (Owen and Murphy 2018a,c). The data make it possible to contrast national accessibility levels with local accessibility levels. Access to jobs is used over other destination types because places of employment represent where other services and activities are performed, thus job access is a good indicator of access to many other important destinations. Minnesota is selected to demonstrate how statewide, regional, and urban geographies compare to one another and to the national averages. The core-based statistical area (CBSA) of Minneapolis-Saint Paul (Twin Cities) provides the regional example while the cities of Minneapolis and Saint Paul provide the urban example. These cities constitute the most dense, central part of the CBSA where the highest concentrations of jobs and transit service exist. The four geographic regions selected for this study demonstrate how detailed cumulative job accessibility datasets can be applied systematically to evaluate the distribution of access across diverse population groups. Repeating this analysis across the country can shed light on regions where access to jobs is evenly or unevenly distributed, and prompt conversations for targeting transportation and land use investments to under-served populations.

We start by providing summary statistics of the studied populations. Next, we compare the average accessibility of each demographic group to the average accessibility of the total worker population at each geography. This comparison is repeated for each set of geographic bounds. The results are presented through a series of figures depicting the percent difference between each demographic groups' average accessibility and the total population's average accessibility. These comparisons show which groups are underperforming or over-performing against the area average when it comes to access to jobs. The conclusion summarizes the main accessibility trends and suggests how the research can be repeated and applied during the transportation and land use planning process.

\section{Literature Review}

The equitable distribution of transportation assets and outcomes has been analyzed using numerous approaches and measures in the literature. Of particular interest are the accessibility outcomes for those in low socio-economic status, minority, and vulnerable groups. Transportation is a significant contributor to the quality of people's lives (Schneider et al. 2013). Planning for an equitable transportation and land use system that provides access to economic opportunities, services, and activities is a key measure of transportation quality (Lee and Sener 2016).

The literature review paper by Lucas et al. (2016) finds that the definition of transport poverty and the related term of accessibility poverty are underdeveloped and under-researched by academics, policy makers, planners and engineers. The paper cites one barrier to accurately defining and addressing accessibility poverty is the lack of data on transport options, affordability, infrastructure, and individual needs. Measuring the ease of reaching jobs as a property of the neighborhood where workers live is one step in targeting resources to under-served areas. Both potential and realized accessibility are important for understanding the economic outcomes of individuals and groups of people. An approach for measuring transport disadvantage by considering accessibility, mobility, and realized travel behavior as complimentary elements for policy and planning is suggested by Pyrialakou et al. (2016).

The juxtaposition of transport systems and land use can exacerbate "spatial mismatch," a concept introduced by John Kain in 1968 to explain low employment and earnings for African Americans living in central cities disconnected from suburban jobs (Kain 1968). The mechanisms, theoretical models, and facts surrounding spatial mismatch are explored in depth by Gobillon et al. (2007). In recent years, several studies have evaluated job accessibility among socially disadvantaged groups. These studies have drawn similar conclusions in contrast to the spatial mismatch hypothesis (El-Geneidy et al. 2016a) (Grengs 2010). An assessment of accessibility, travel mode, and social groups in Detroit, Michigan finds that despite "high job sprawl, severe segregation by race and income, and a decentral- 
ized pattern of accessibility" African Americans and low-income households tend to live where accessibility is high. The author finds that $80 \%$ of Black households experience better accessibility than white households, but the remaining $20 \%$ experience extreme disadvantage when accessibility is based on car ownership.

Similar trends exist for Hispanic and low-income households (Grengs 2012). A study by ElGeneidy et al. (2016b) in Montreal, Canada used both time and costs of travel to measure accessibility to jobs for neighborhoods across socio-economic backgrounds. Socially disadvantaged groups are found to have better transit access compared with the advantaged group, although the degree of benefit varies throughout the day. Foth et al. (2013) examines transit accessibility from 1996-2006 in Toronto, Canada and compares three equity measures to determine the change in transit equity over time. The authors find that the most disadvantaged areas of Toronto experience lower transit travel times and better accessibility than the region as a whole from 1996 to 2006. An analysis of job accessibility and employment for auto-less and low-skilled households is conducted for Boston, San Francisco, and Los Angeles (Kawabata 2003). The study finds that better transit accessibility in the urban areas of highly auto-dependent metropolitan regions increases the likelihood of low-skilled auto-less workers to be employed and work more than 30 hours a week. The findings suggest that spatial mismatch, does not hold in central-city areas where accessibility is consistently higher than in suburban areas.

Studies relevant to the research presented here have been conducted in the Twin Cities on prior occasions. The introduction of the Blue Line light rail transit route to the Twin Cities in 2004 prompted Fan et al. (2012) to assess the accessibility impact of new transit service for workers in various income groups. The article specifically addresses the spatial mismatch of low-wage workers and low-wage jobs in the Twin Cities. It was found that all workers gain accessibility with the added light rail line. Lowwage workers near stops in Minneapolis and on the north end of the line significantly gained access to low-wage jobs with the addition of the light rail line. Outside of these areas, low-wage workers gained less than their medium to high-wage counterparts.

\section{Data}

\subsection{Geography and population}

Minnesota is located in the Upper Midwest region of the United States. Approximately two million Minnesotans or $36 \%$ of the population live in rural areas. Another 3.5 million live in the Twin Cities metropolitan region making it the 16th largest metro area in the United States. The Twin Cities can be characterized by a core urban area surrounded by sprawling suburban landscapes. Major industries in Minnesota include healthcare and medical equipment, high technology, finance and insurance, forest products, printing and publishing, food products, and iron ore mining ${ }^{1}$.

Data for 2015 describing the distribution of labor and employment in the study regions are drawn from the U.S. Census Bureau's Longitudinal Employer-Household Dynamics program (LEHD) ${ }^{2}$. This data year corresponds with the LEHD data year applied in the 2017 National Accessibility Evaluation data used in this study (the latest available at the time of this research). The LEHD Origin-Destination Employment Statistics (LODES) dataset, which is updated annually, provides Census block-level estimates of employee home and work locations. Table 1 provides the total number of blocks, workers, and jobs contained within each geographic region. It can be seen that the urban core contains far more jobs than workers, indicating that residents throughout the Twin Cities may commute longer distances to reach the bulk of jobs in the region.

Five demographic groups are selected for the evaluation of worker-weighted accessibility including age, monthly earnings, educational attainment, race, and sex. The groups are derived from the

\footnotetext{
${ }^{1}$ https://www.exploreminnesota.com/media/facts-figures

${ }^{2}$ http://lehd.ces.census.gov/data/
} 
Table 1: The number of Census blocks, workers, and jobs corresponding with the 2015 LODES dataset for each geographic region used in this study.

\begin{tabular}{lrrrr} 
& Nation & Minnesota & Twin Cities & Urban Core \\
\hline Blocks & $11,166,336$ & 240,553 & 66,659 & 10,466 \\
Workers & $137,705,053$ & $2,773,855$ & $1,794,785$ & 345,241 \\
Jobs & $137,705,053$ & $2,778,583$ & $1,841,690$ & 529,551
\end{tabular}

LODES dataset. The number and percent of total workers falling within each group are listed in Table 2. Across all geographic regions, the proportion of workers in each group is approximately the same. The educational attainment group is only available for workers age 30 and older meaning the percent of total workforce values do not add up to $100 \%$. Each race group is exclusive other than the Races 2+ group which counts workers of two or more races.

It can be seen that Minnesota and the Twin Cities and urban core regions generally have similar proportions of workers from each demographic group as the nation. Workers between the ages of 30 and 54, workers earning more than $\$ 3,333$ per month, and workers who are White are the most prevalent at all geographic scales. Minnesota varies from the nation in the higher proportion of workers with post-secondary education and with $1.4 \%$ more female workers than male workers.

Table 2: The number and percent of workers within four geographic levels for each demographic group corresponding to the 2015 LODES dataset.

\begin{tabular}{lrrrr} 
& Nation & Minnesota & Twin Cities & Urban Core \\
\hline Age $<=29$ & $31,008,246(22.5 \%)$ & $650,567(23.5 \%)$ & $415,248(23.1 \%)$ & $96,451(27.9 \%)$ \\
Age 30-54 & $75,608,939(54.9 \%)$ & $1,503,978(54.2 \%)$ & $998,633(55.6 \%)$ & $187,183(54.2 \%)$ \\
Age $>=55$ & $31,087,868(22.6 \%)$ & $619,310(22.3 \%)$ & $380,904(21.2 \%)$ & $61,607(17.8 \%)$ \\
\hline Earn $<=\$ 1,250 / \mathrm{mth}$ & $32,898,003(23.9 \%)$ & $674,354(24.3 \%)$ & $404,123(22.5 \%)$ & $84,319(24.4 \%)$ \\
Earn $1,2513,333 / \mathrm{mth}$ & $46,722,274(33.9 \%)$ & $818,485(29.5 \%)$ & $482,974(26.9 \%)$ & $107,894(31.3 \%)$ \\
Earn $>=\$ 3,333 / \mathrm{mth}$ & $58,084,776(42.2 \%)$ & $1,281,016(46.2 \%)$ & $907,688(50.6 \%)$ & $153,028(44.3 \%)$ \\
\hline Edu. $<$ HS & $13,753,051(10.0 \%)$ & $170,707(6.2 \%)$ & $107,708(6.0 \%)$ & $23,881(6.9 \%)$ \\
Edu. $=$ HS & $28,737,324(20.9 \%)$ & $580,766(20.9 \%)$ & $346,636(19.3 \%)$ & $60,823(17.6 \%)$ \\
Edu. $<=2$ yr & $33,837,988(24.6 \%)$ & $723,687(26.1 \%)$ & $454,383(25.3 \%)$ & $79,395(23.0 \%)$ \\
Edu. $>=4$ yr & $30,368,444(22.1 \%)$ & $648,128(23.4 \%)$ & $470,810(26.2 \%)$ & $84,691(24.5 \%)$ \\
\hline White & $109,892,890(79.8 \%)$ & $2,468,859(89 \%)$ & $1,542,398(85.9 \%)$ & $261,525(75.8 \%)$ \\
Black/Afr.Amer. & $17,442,487(12.7 \%)$ & $140,289(5.1 \%)$ & $123,997(6.9 \%)$ & $46,896(13.6 \%)$ \\
Amer. Indian/Alaskan Native & $1,200,290(0.9 \%)$ & $23,684(0.9 \%)$ & $9,845(0.5 \%)$ & $3,029(0.9 \%)$ \\
Asian & $6,938,655(5.0 \%)$ & $105,853(3.8 \%)$ & $92,498(5.2 \%)$ & $26,274(7.6 \%)$ \\
Hawaiian/Pacific Islander & $243,349(0.2 \%)$ & $1,727(0.1 \%)$ & $1,305(0.1 \%)$ & $354(0.1 \%)$ \\
Races 2+ & $1,987,382(1.4 \%)$ & $33,443(1.2 \%)$ & $24,742(1.4 \%)$ & $7,163(2.1 \%)$ \\
\hline Male & $69,010,501(50.1 \%)$ & $1,361,454(49.1 \%)$ & $885,395(49.3 \%)$ & $170,187(49.3 \%)$ \\
Female & $68,694,552(49.9 \%)$ & $1,412,401(50.9 \%)$ & $909,390(50.7 \%)$ & $175,054(50.7 \%)$
\end{tabular}

\subsection{Accessibility}

The National Accessibility Evaluation project produces annually updated cumulative accessibility to jobs data for the entire United States by automobile and transit, as well as biking and walking ${ }^{3}$. Accessibility results for 49 of the 50 largest (by population) metropolitan areas in the United States are analyzed in the Access Across America series of reports. The methods for calculating automobile and transit travel times can be found in the Access Across America methodology reports (Owen and Murphy 2018b,d). Data for 2017 during the morning rush hour are used in this research. Automobile accessibility accounts for congestion related speed impacts. Transit accessibility assumes pedestrian

\footnotetext{
${ }^{3}$ http://access.umn.edu/
} 
connections and includes unlimited transfers between routes. Finally, transit accessibility accounts for service frequency by calculating accessibility at every minute during the morning peak and taking the average. In this research, we apply the travel time-weighted measure which weights accessibility at shorter travel time thresholds more than at longer travel time thresholds.

Cumulative accessibility for the Twin Cities is shown in Figures 1 and 2. The maximum number of jobs accessible by transit in the Twin Cities is approximately 500,000 within 30 minutes of travel, while automobile reaches approximately 2.5 million in the same travel time. These differences are due to broad coverage of surface roads compared to fixed transit routes and frequencies. The disparity in transit and automobile accessibility to jobs is consistent across metropolitan regions in the United States (Owen and Murphy 2018c).
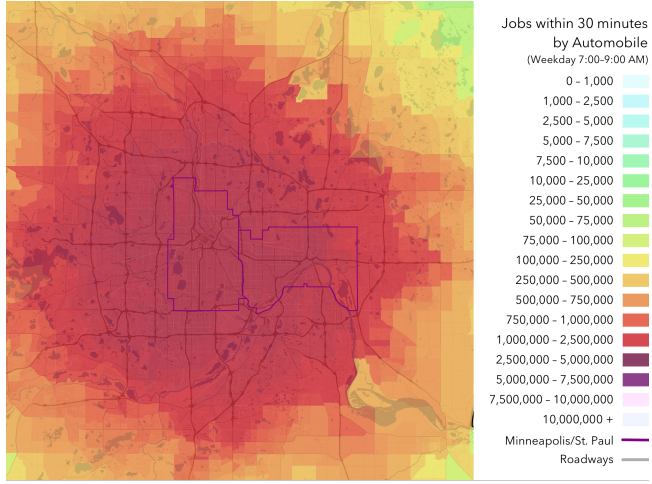

Figure 1: The overall worker-weighted accessibility to jobs in the Twin Cities by automobile within 30 minutes of travel, weekday 7-9 AM.

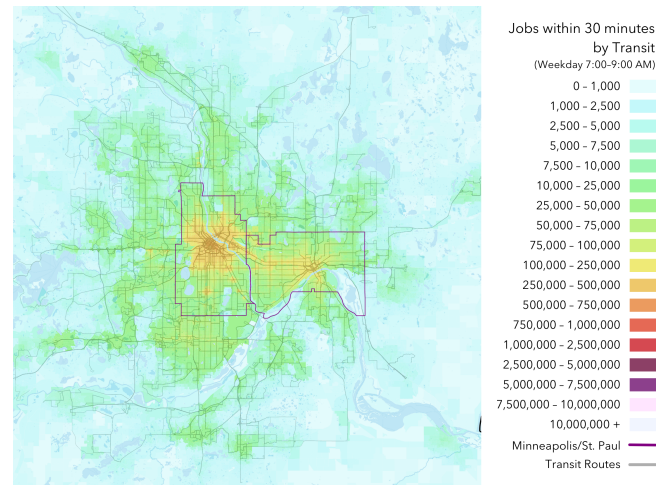

Figure 2: The overall worker-weighted accessibility to jobs in the Twin Cities by transit within 30 minutes of travel, weekday 7 9 AM.

\subsection{Worker-Weighted Average Accessibility}

Cumulative accessibility is a locational metric rather than an individual metric--it describes properties of places within each geographic region, rather than properties of their residents (Horner 2004). However, the value of accessibility is only realized when it is experienced by people. To reflect this fact, when accessibility is averaged across multiple blocks in a large area, each block's contribution is weighted by the number of workers in that block. The result is a single metric that represents the accessibility value experienced by the average worker in the study area. For example, a worker-weighted accessibility value of 134,173 indicates that the average worker within the study area can reach 134,173 jobs. Here, the worker-weighted accessibility is computed using the travel-time-threshold-weighted accessibility value. Cumulative accessibility weighted by travel time threshold and resident worker population is the primary metric by which national accessibility levels are compared with state, CBSA, and urban regions in this study. We repeat the worker-weighted accessibility calculation for each demographic group to get the average accessibility experienced by different groups of workers.

\section{Results}

A comparative analysis of worker-weighted average accessibility for four geographies and five demographic categories is presented. Block-level accessibility data for national, state, regional, and urban geographies are disaggregated by resident worker age, monthly earnings, educational attainment, race, and sex. Each demographic groups' average accessibility is centered on the entire worker population's 
average accessibility for the selected region. For example, the average accessibility of young workers at the state level is compared to the average accessibility of all workers at the state level, regardless of age.

The difference between demographic groups is shown in reference to the entire worker population's average accessibility, also referred to as the population average. A positive or negative percent difference from the population average indicates a specific worker demographic group with higher or lower job accessibility compared to the population average. The results for automobile and transit are presented together to compare trends in the data. For reference, the total worker-weighted average accessibility for automobile and transit modes is shown in Figure 3. The magnitude of accessibility shown for automobile and transit at each geographic scale are the values used to center demographic worker-weighted accessibilities.

auto Transit

350,000

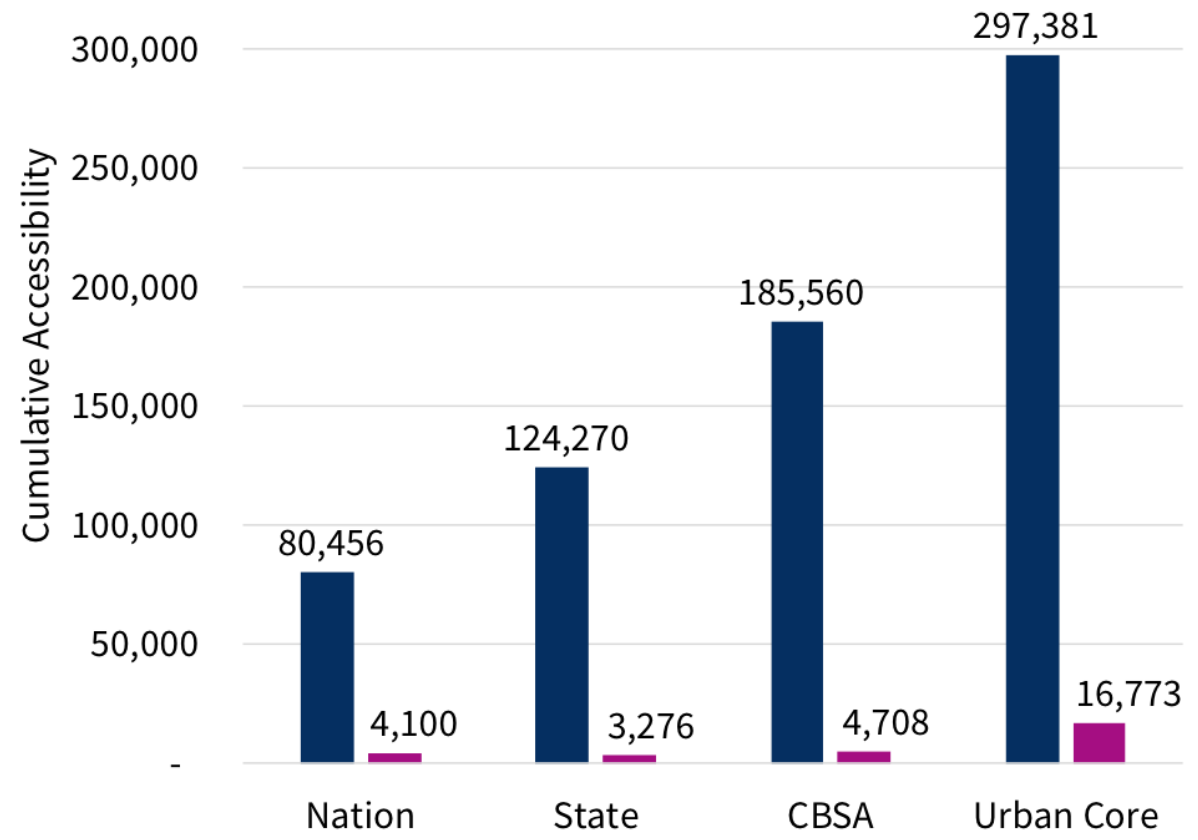

Figure 3: The total worker-weighted average accessibility to jobs for automobile and transit modes. 


\subsection{Age}

The LODES dataset divides workers into three age groups: workers under the age of 30, workers between the ages of 30 and 54, and workers age 55 and older. At all geographies, the average worker under 30 experiences higher automobile and transit accessibility to jobs compared with the population average. Workers in this age group may systematically live in areas that provide higher accessibility to jobs either through proximity to jobs from home location, or through good mobility by private vehicle and transit services.

For middle-aged workers, average accessibility varies from the population average by $+0.8 \%$ to $4.1 \%$ depending on geographic region and mode. In contrast, the oldest workers experience $-0.2 \%$ to $-16.0 \%$ lower accessibility by automobile and transit than the population average. The national trend for older workers shows negative percent differences from the population average by automobile and transit. That trend is stronger at the state level, then scales back at the CBSA and urban levels, but older workers always remain below the population average. From this trend it can be seen that older workers across the country and the state of Minnesota live on average farther from jobs or fast transportation options than older workers in increasingly more urbanized areas such as the Twin Cities and urban core. Regardless of mode, older workers are at an apparent disadvantage when it comes to competitive job accessibility levels with younger workers. The worker-weighted accessibility results for automobile and transit by age are shown in Figures 4 and 5 .

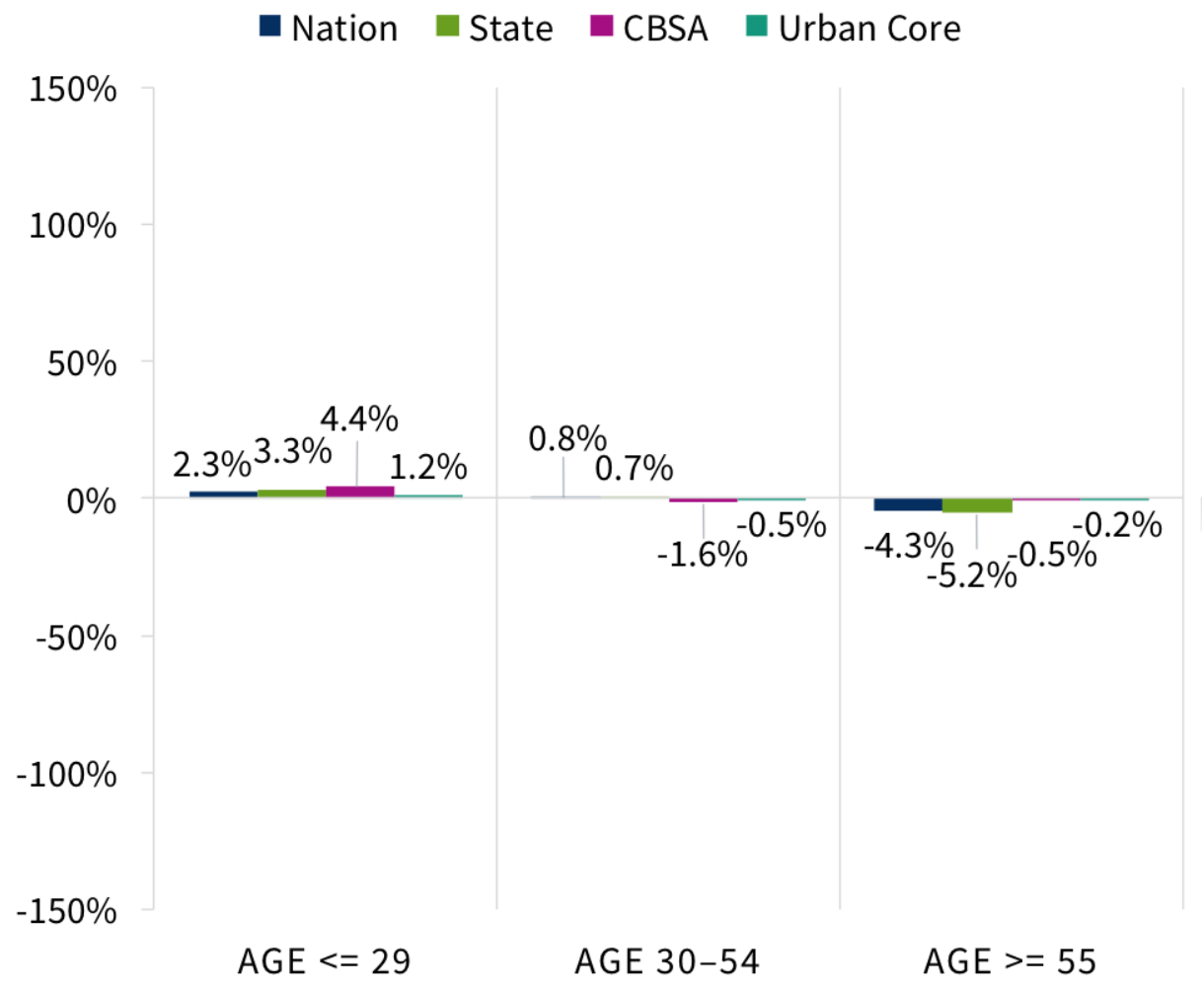

Figure 4: Average automobile accessibility experienced by workers in each age group centered on the overall average workers' accessibility.

\subsection{Monthly Earnings}

The LODES dataset divides workers into three income groups: workers earning less than or equal to $\$ 1,250$ per month, workers earning between $\$ 1,251$ and $\$ 3,332$ per month, and workers earning at least $\$ 3,333$ per month. 


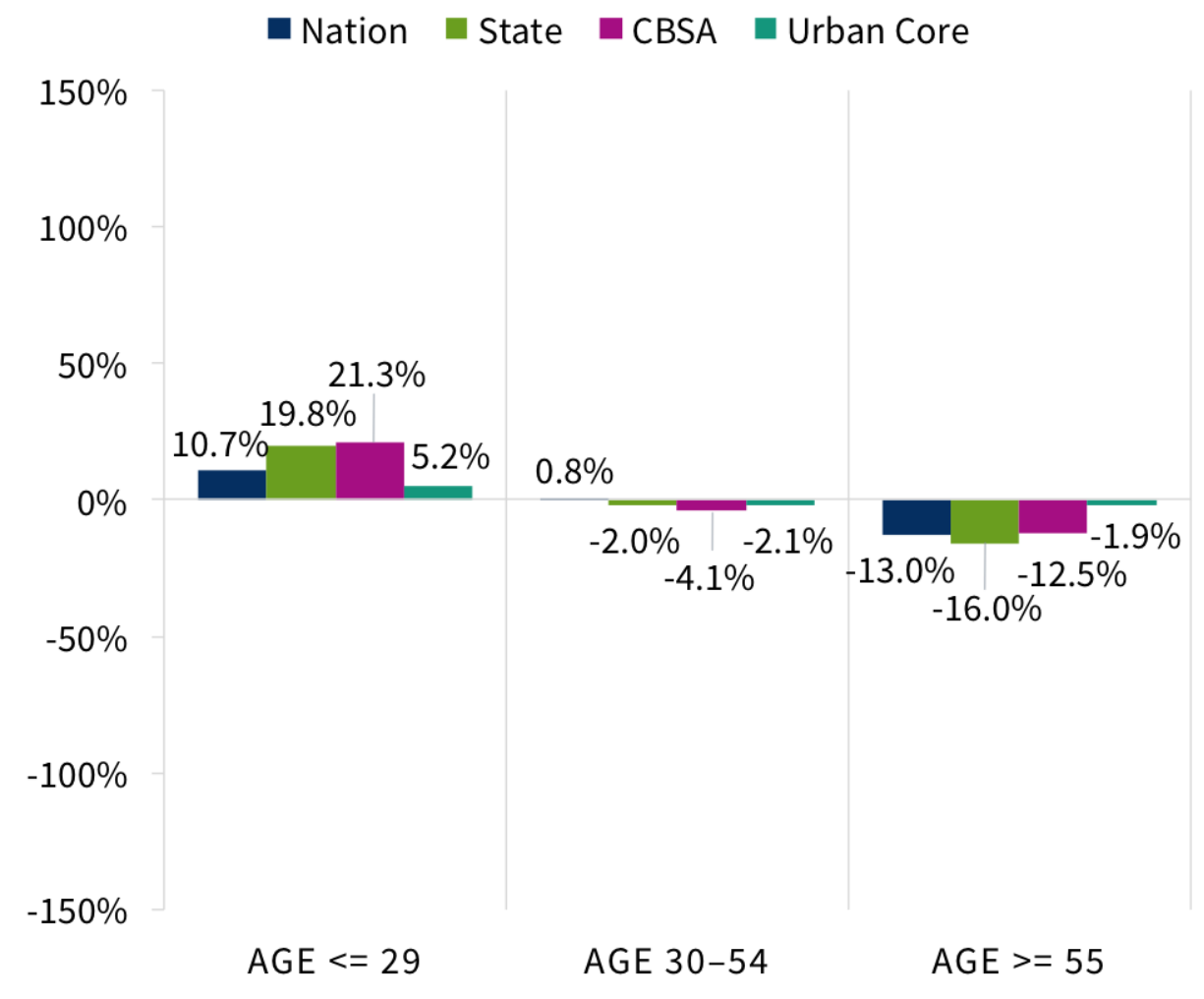

Figure 5: Average transit accessibility experienced by workers in each age group centered on the overall average workers' accessibility.

For the low and middle earning worker groups at the national level, accessibility to jobs by automobile is lower than the population average by $-3.7 \%$ and $-3.3 \%$ respectively. The state of Minnesota shows an intensified trend from the national level-low and middle earning workers experience $-6.2 \%$ and $-5.4 \%$ difference from the population average respectively. The CBSA and urban geographies show nearly a complete reversal of the national and state trends. That is, low and middle earning workers differ from the population average job accessibility by $-0.5 \%$ to $+2.9 \%$ - meaning developed areas offer lower earning workers more jobs or better transportation. Additionally, in the Twin Cities and urban core areas the highest earning workers exhibit differences from the population average of $-1.8 \%$ to $+0.2 \%$. The data indicate that access to jobs by automobile is more evenly distributed among workers of different earning status in developed geographies than in less developed geographies.

For low and middle earning workers, transit accessibility at the national level is below the population average. However, the state, CBSA, and urban geographies each show a nearly complete reversal of the national trend for transit accessibility. Transit service and workers' proximity to jobs throughout the state provide low and middle earning workers with above average job accessibility by $+0.9 \%$ to $+2.9 \%$, while the highest earning workers collectively fall below the population average by $-2.3 \%$.

The statewide accessibility levels are intensified at the CBSA level where low and middle earning workers exceed the population average by $+7.5 \%$ to $+11.4 \%$. The urban core exhibits smaller differences from the population average because transit service is most extensive at this geography than at larger areas. Low earning workers in the urban core experience above average job accessibility by $+1.8 \%$ - faring better than low earning workers nationwide. In general, the state of Minnesota provides better than average transit accessibility to jobs for low and middle income workers compared with the highest earners. This is in contrast to the national accessibility levels for each earning range. The worker-weighted accessibility results for automobile and transit by monthly earnings are shown in Figures 6 and 7. 


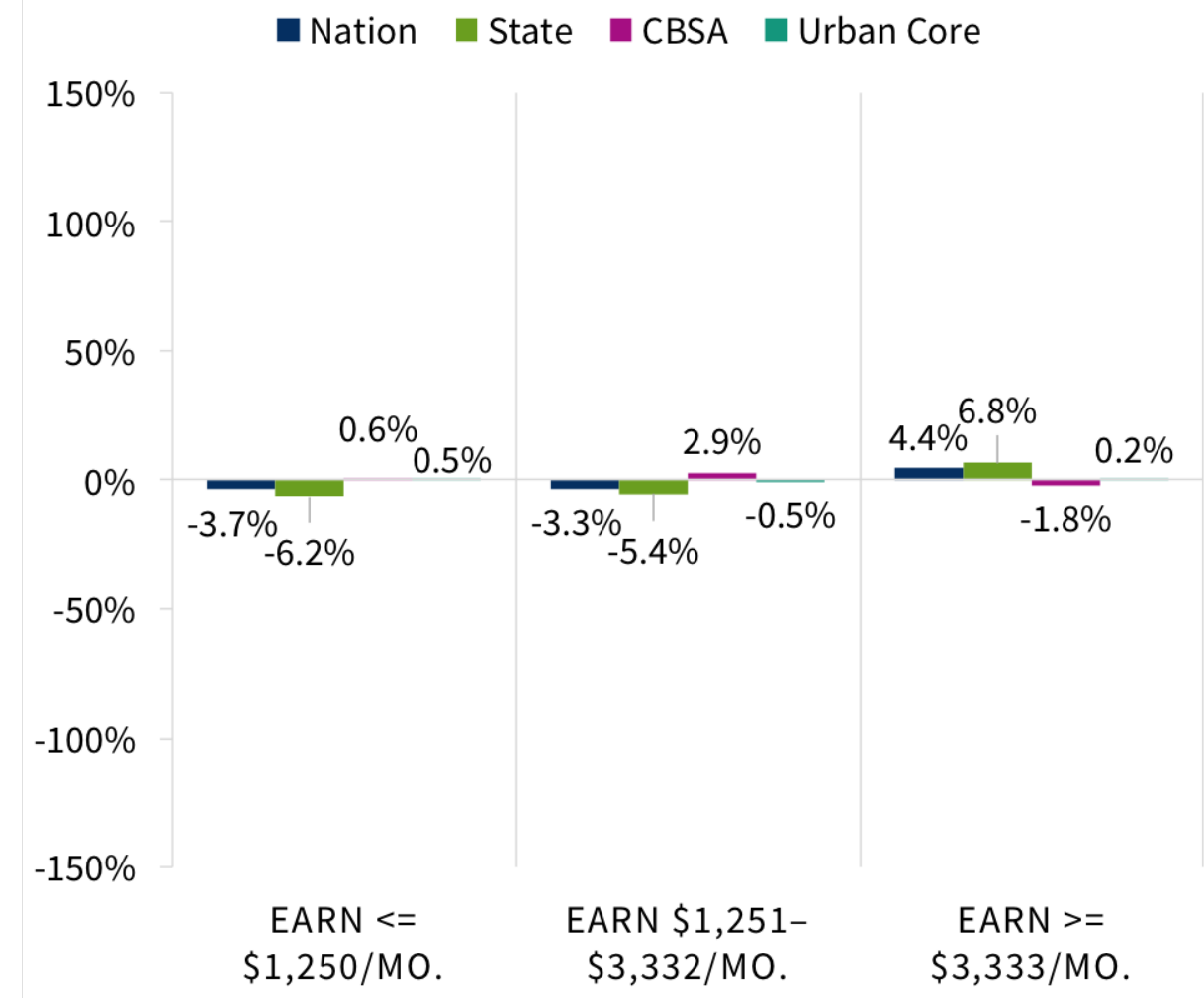

Figure 6: Average automobile accessibility experienced by workers in each monthly earnings group centered on the overall average workers' accessibility.

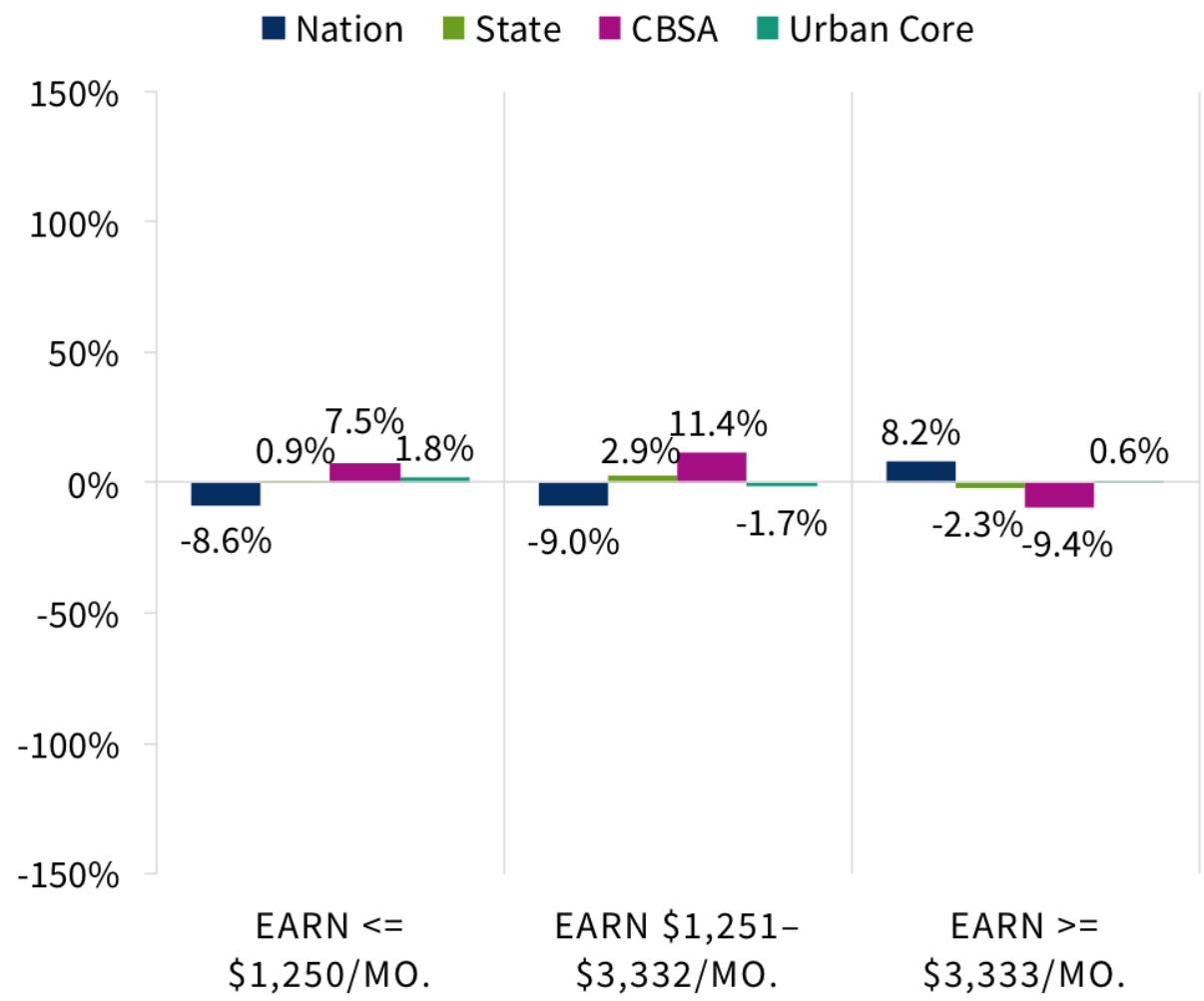

Figure 7: Average transit accessibility experienced by workers in each monthly earnings group centered on the overall average workers' accessibility. 


\subsection{Educational Attainment}

The LODES dataset divides workers into four educational attainment groups: workers with less than a high school diploma, workers with a high school diploma, workers holding a high school diploma or up to two year of post-secondary education, and workers holding a bachelor's degree or higher. The Census Bureau only records educational attainment for workers age 30 and older. This influences the results at small geographies such as the urban core where accessibility is below average for all worker education groups because the accessibility found for young workers is not included.

A clear trend is found for workers who achieved a high school education up through an associates degree. At all geographies, these workers experience lower than average job accessibility levels by both automobile and transit. Meanwhile, the least and most educated workers tend to exhibit higher than average job accessibility by automobile and transit, especially at the state and national level. The groupings may be attributed to similarities in residential choice. The lowest and highest educated may live in more diversified areas where housing is closer to jobs and the transportation networks are well developed. Those with a high school diploma through associates degree may live in neighborhoods that are cut off from other land uses; where mobility by automobile and transit is poor; or where both occur. The state of Minnesota tends to follow if not exceed the national trend when it comes to workers who experience above or below average accessibility levels.

Transit accessibility at the national level for the least educated exceeds the population average by $+1.5 \%$ while the state and CBSA exceed their population averages by $+7.2 \%$ to $+10.2 \%$ respectively. These results indicate that Minnesota is connecting its least educated workers with the most jobs via transit compared with higher educated workers-and that percentage difference exceeds the national level.

At the national level, transit accessibility for those with a high school diploma or post-secondary education ranges from $-8.0 \%$ to $-11.8 \%$ below the population average. The state of Minnesota shows an exacerbated trend when it comes to transit accessibility for moderately educated workers, that being a $-11.2 \%$ to $-14.6 \%$ difference from the population average. The reason for the lack of accessibility may be related to the job types held by those with less than a bachelor's degree. Agricultural, construction, manufacturing, and mining jobs may require formal training yet are located further from the urban regions, thereby attracting workers that live in outlying areas. Segmenting the accessibility results by job type and performing a spatial comparison of worker and job locations may reveal how this trend comes into existence both within the state of Minnesota and in the nation.

One significant difference between local geographies and the national average for transit accessibility is with workers in the highest education category. At the national level, the highest educated workers exceed the population average by $+6.0 \%$, but at the CBSA level, workers are below the population average by $-5.9 \%$. This difference is worth noting; however, more data and research are needed to understand what factors contribute to deviations from the national trend. The worker-weighted accessibility results for automobile and transit by educational attainment are shown in Figures 8 and 9.

\subsection{Race}

The LODES dataset divides workers into six racial groups, including White, Black and African American, American Indian and Alaskan Native, Asian, Native Hawaiian and Pacific Islander, and two or more race groups. The results for automobile accessibility by worker race at the national level are closely followed if not exceeded by the results found for the state. For White workers, the difference in accessibility from the population average is $-5.1 \%$ at the national level and varies from $+0.4 \%$ to $-6.7 \%$ for Minnesota geographies. The results indicate that White workers across the country tend to live in locations where jobs are less accessible. A majority of non-White worker groups experience above average accessibility levels at the national, state, and CBSA levels. In the state of Minnesota, minority 


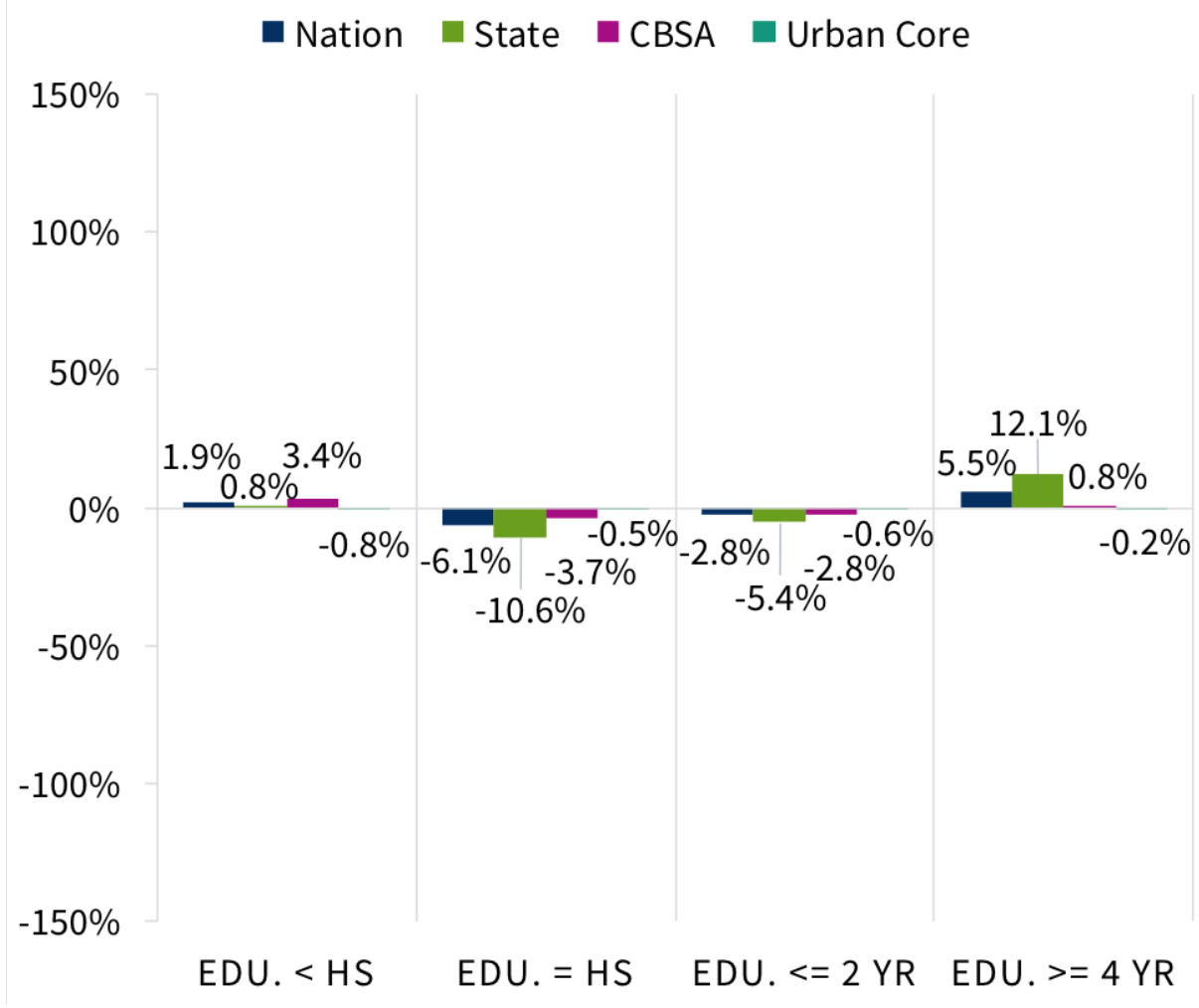

Figure 8: Average automobile accessibility experienced by workers in each educational attainment group centered on the overall average workers' accessibility.

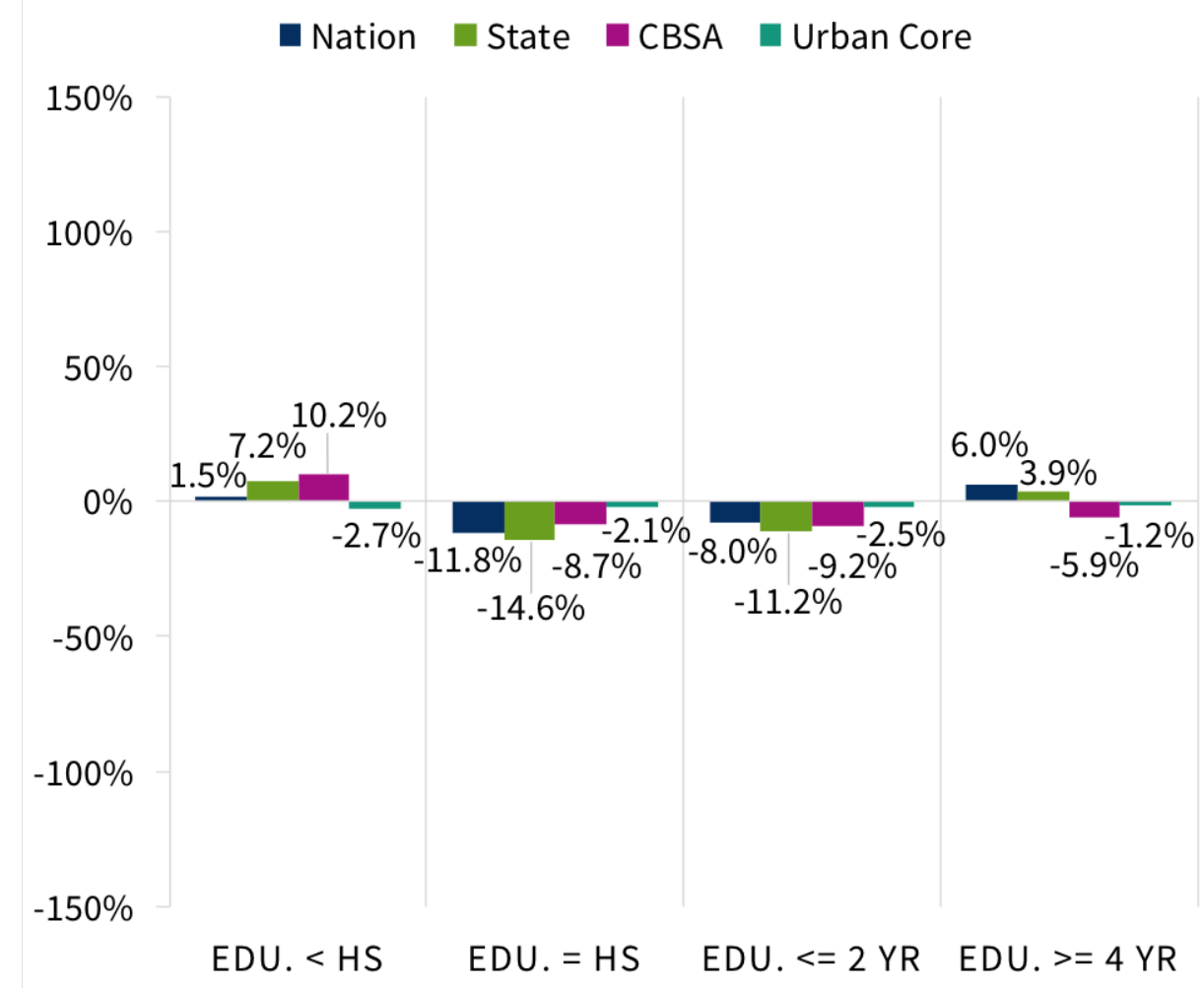

Figure 9: Average transit accessibility experienced by workers in each educational attainment group centered on the overall average workers' accessibility. 
worker groups exceed the population average by $+29.6 \%$ to $+75.1 \%$. American Indian and Alaskan Native workers are the only groups that fall below the population average at some geographies.

Results for the urban core show much smaller percent differences from the population average accessibility level. In fact, some trends found at larger geographies change direction at the urban level including the results for White, Asian, and multiracial workers. The reasons for this change are not apparent from the data, but further examination of where these groups live in the urban core may reveal patterns in residential choice and the surrounding transportation and land uses.

The accessibility results for transit are clear across all non-White worker groups. The non-White workers in the nation, state, and CBSA experience higher accessibility to jobs by transit compared to their population averages while White workers experience below average accessibility levels. Black and African American workers experience accessibility to jobs by transit exceeding the population average by $+4.1 \%$ to $+145.5 \%$ depending on the geography. The difference between White and Black workers' job accessibility by transit is remarkable, but further analysis is needed to understand how these trends originate and if they translate to realized accessibility.

The percent differences remain positive and large for Asian, Hawaiian, and multi-racial workers. American Indian and Alaskan Native workers experience job accessibility that far exceeds the population average at the CBSA level, yet this group falls below average at the state level. The below average accessibility can be attributed to the concentration of American Indian and Alaskan Native workers on reservations or tribal lands which have low transit access to jobs in greater Minnesota. Overall, transit accessibility to jobs for non-White worker groups across the nation exceeds the population average by substantial amounts. The worker-weighted accessibility results for automobile and transit by race are shown in Figures 10 and 11.

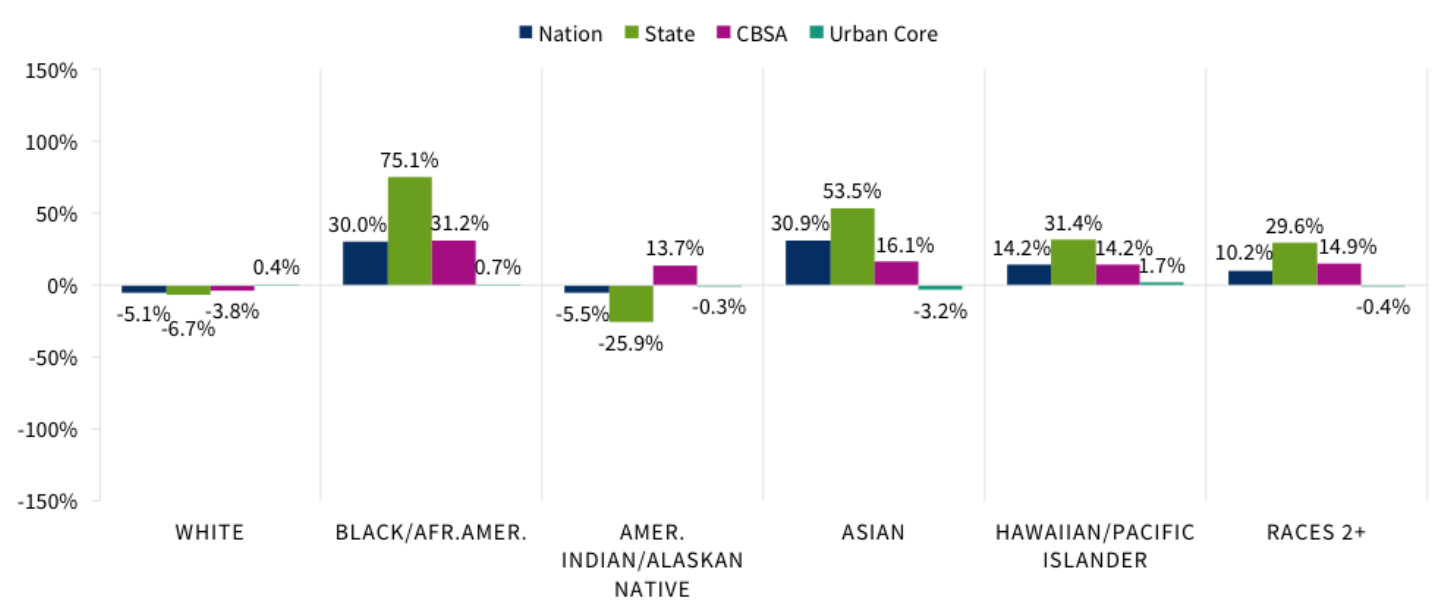

Figure 10: Average automobile accessibility experienced by workers in each race group centered on the overall average workers' accessibility.

\subsection{Sex}

The LODES dataset divides workers into male and female groups. Compared to other demographic groups, there is significantly less variation among geographies from the population average accessibility. There are no discernible differences between male and female worker-weighted average accessibilities at the national level. At the statewide and urban levels, male workers experience higher automobile accessibility than female workers. At the CBSA level, female workers experience higher automobile accessibility. These small differences are likely related to residential patterns for male and female workers. It is not clear from the data why male workers experience higher job accessibility by automobile at the state and urban levels. 


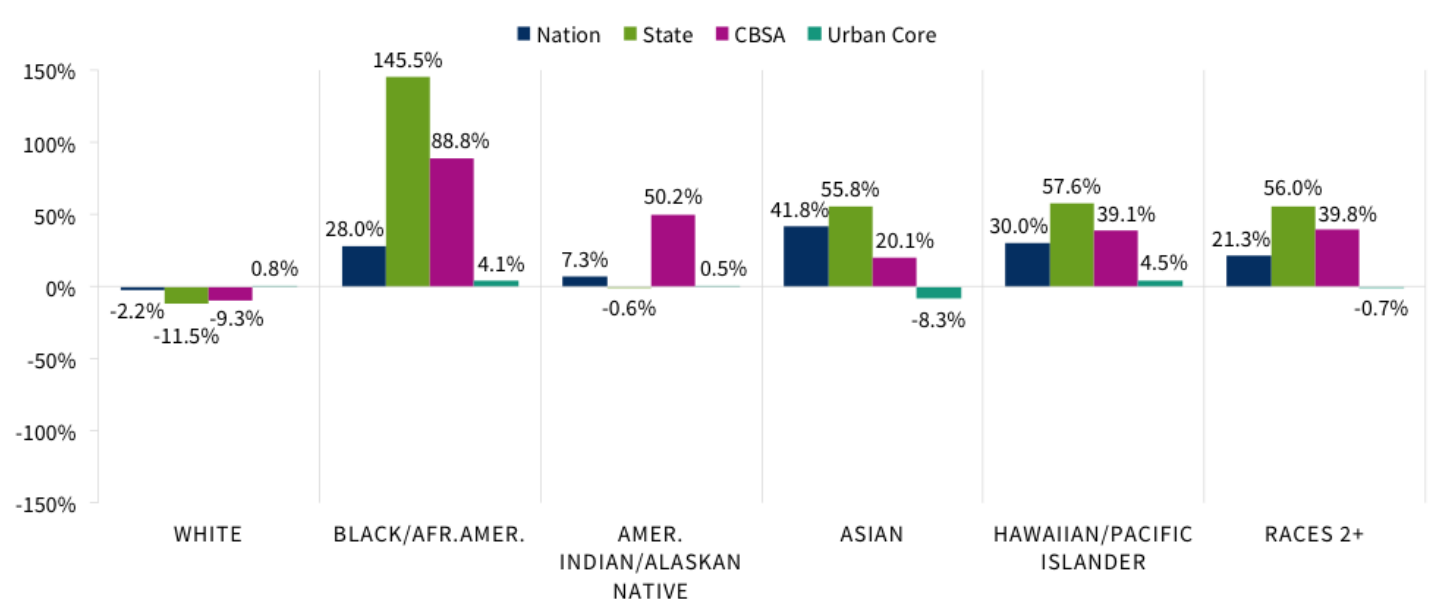

Figure 11: Average transit accessibility experienced by workers in each race group centered on the overall average workers' accessibility.

The transit results show that at all geographies, female workers experience lower accessibility to jobs by $-1.0 \%$ to $-1.5 \%$ compared to the population average. Male workers constitute the second half of the population average calculation, and they experience higher accessibility by $+1.0 \%$ to $+1.6 \%$. Women make up at least $50 \%$ of transit ridership across the nation, and in many cases the percentage is higher. Given the need for transit, female workers' consistent disparity in access to jobs is worth further investigation as to the systemic factors at play nationally and locally. The worker-weighted accessibility results for automobile and transit by sex are shown in Figures 12 and 13.

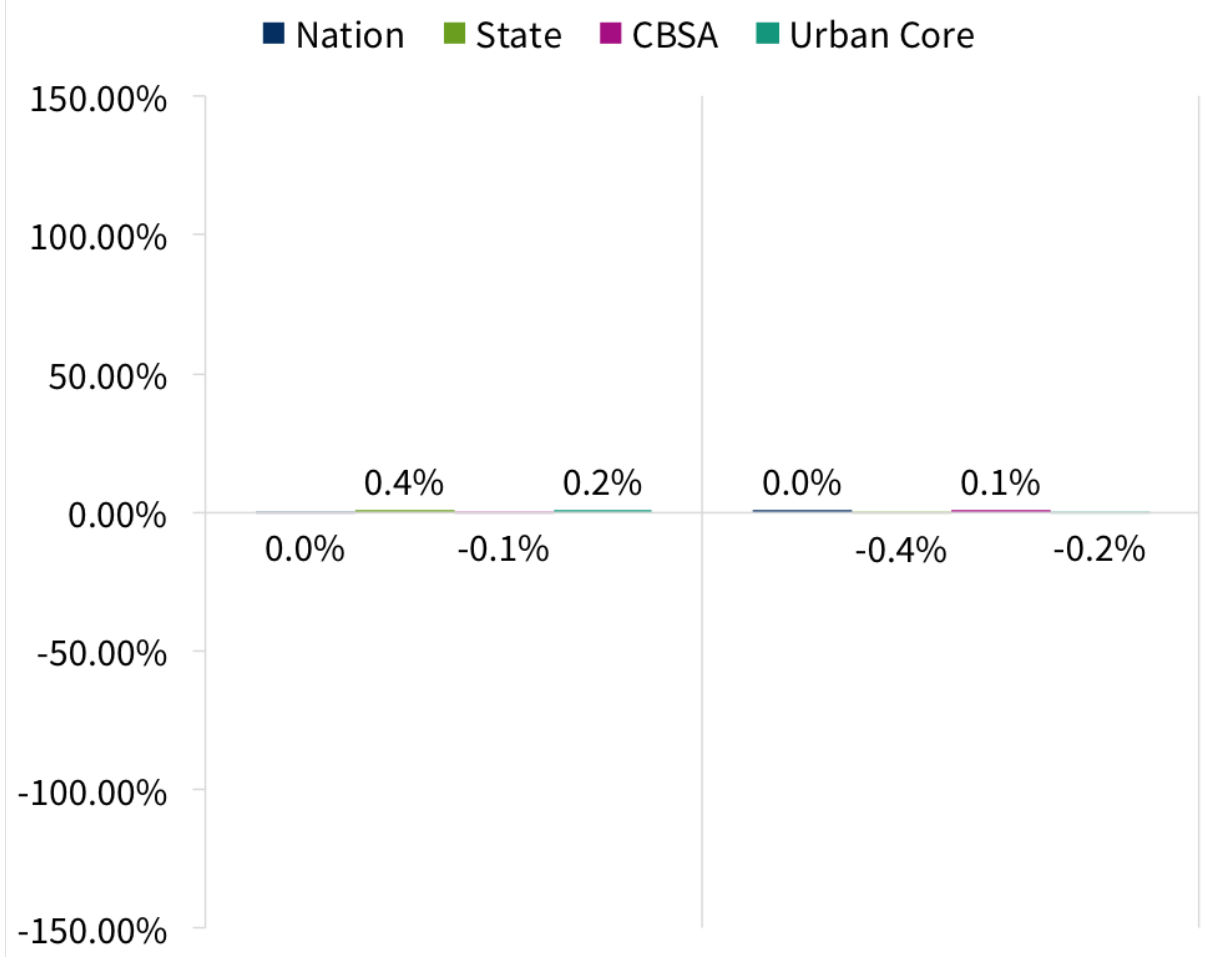

MALE

FEMALE

Figure 12: Average automobile accessibility experienced by workers of each sex compared with the overall average workers' accessibility. 


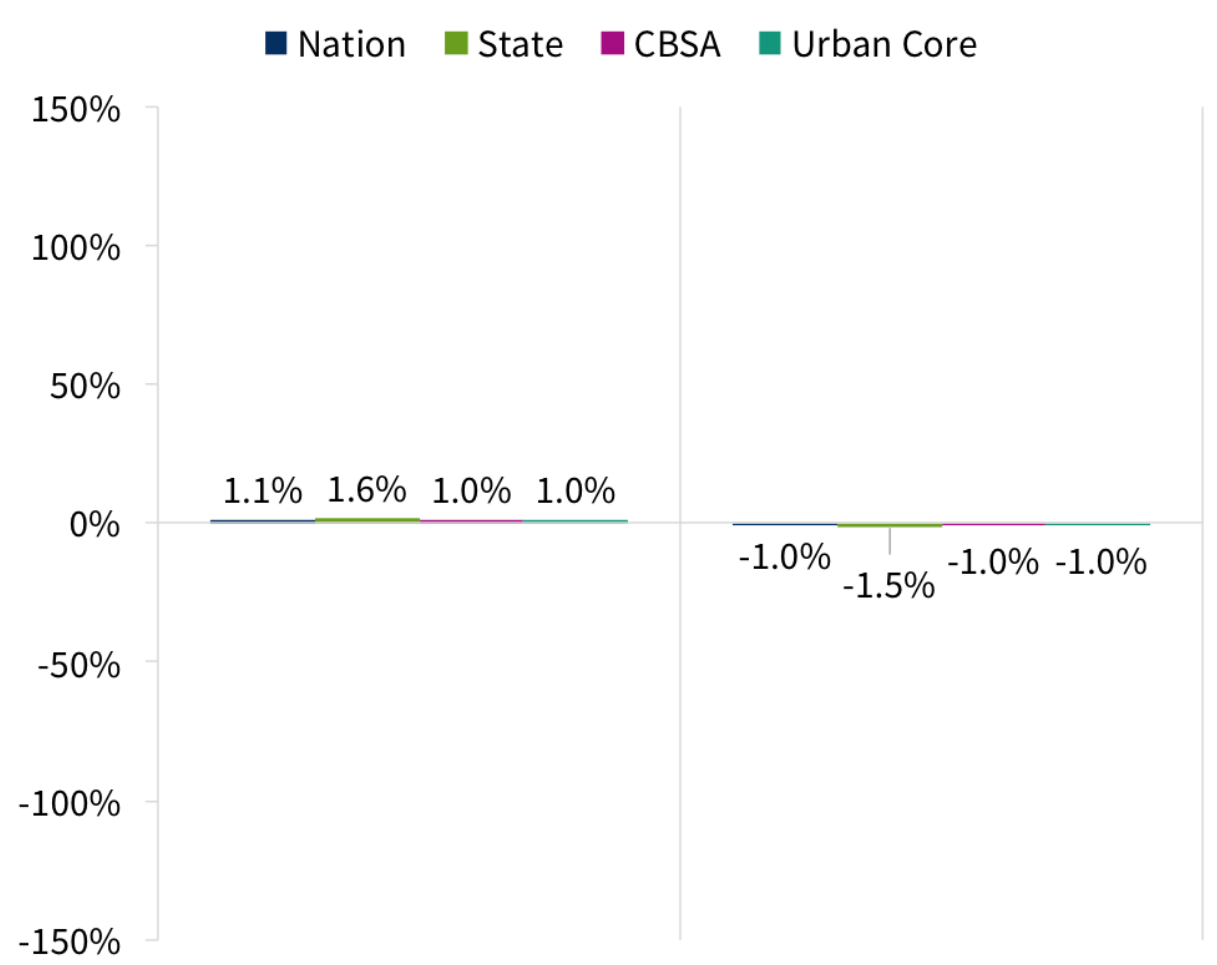

MALE

FEMALE

Figure 13: Average transit accessibility experienced by workers of each sex compared with the overall average workers' accessibility.

\section{Conclusion}

The demographic worker-weighted accessibility analysis and results presented in this paper provide insight to the national and regional differences in accessibility by automobile and transit. National datasets on worker demographics and accessibility to jobs are combined to learn where and for whom accessibility is lower, equal to, and higher than the population average accessibility. The state of Minnesota and its metropolitan and urban areas are used to demonstrate how various geographic extents can be compared to each other and the nation when it comes to demographic accessibility trends. Repeating this analysis across the country can shed light on regions where access to jobs is evenly or unevenly distributed, and prompt conversations for targeting transportation and land use investments to under-served populations.

It was found that national accessibility levels for each demographic group tend to match with the levels of accessibility found at the state level. But the results show consistent differences between the state and CBSA worker-weighted accessibilities. The difference may be attributed to the rural nature of Greater Minnesota where jobs, workers, and transportation options are increasingly spread outsimilar to national patterns. Each demographic category explored in this paper exhibits a trend worth more investigation. They are the following:

- At all geographies, the average worker under 30 experiences higher automobile and transit accessibility to jobs compared with older worker groups.

- Nationally, the highest earning group experiences the greatest job accessibility by automobile and transit. 
- At all geographies, workers that hold a high school diploma through associates degree experience lower accessibility to jobs by automobile and transit compared with the lowest and highest educated groups.

- Non-White workers experience higher accessibility to jobs by automobile and transit compared to White workers at nearly all geographies.

- Female workers experience lower accessibility to jobs by automobile and transit compared to male workers at nearly all geographies.

Regional differences in transit networks and worker home location choice is reflected in the average accessibility outcomes at each geography. The worker-weighted measure gives the accessibility potential for a particular origin regardless of personal means. The levels of automobile job accessibility found for some low socio-economic status, minority, and vulnerable groups can only be realized for those workers with access to a vehicle. Additionally, by measuring accessibility based on a single resource, only a portion of the accessibility profile for workers is described. The study by El-Geneidy et al. (2016b) finds that accessibility to jobs using time-based measures is useful for understanding where improvements can be made to transit, bicycle, pedestrian, and automobile infrastructure, but including the monetary costs of travel is key to understanding the realized accessibility of travelers: "Job accessibility research that ignores transit fares, may overestimate job accessibility, particularly for low-income riders."

Several limitations to the data and findings exist. The comparisons made here are based on cumulative access to all jobs; however, only certain job types are relevant to each worker. A deeper exploration of which jobs workers can reach may better describe the accessibility felt by various population groups. Additionally, the LEHD worker data does not support cross-tabular comparisons. For instance, accessibility levels for low earning and White workers versus high earning and White workers cannot be discerned from the data. An analysis of this sort paired with local data on neighborhood characteristics could help target interventions for accessibility improvement. Finally, the LEHD data captures only currently-employed workers on taxable payroll, thereby missing some workers in a potentially disproportionate way to the existing data.

The accessibility results presented here show that some disadvantaged groups such as older, lower earning, moderately educated, and female workers tend to experience lower levels of automobile and transit accessibility compared to their counterparts. The transportation networks and the availability of housing and jobs in close proximity can both contribute to improving accessibility outcomes for these groups. Minority workers are found to experience much higher levels of automobile and transit accessibility than White workers-a finding that has been made in the literature on previous occasions. The distribution of access to jobs among worker populations can be explored in greater depth by segmenting the job sectors used in the accessibility calculation. The added detail may highlight how workers and jobs are connected through the transportation and land use system or which jobs are located with a low barrier to entry via current transportation options among different workers.

The data analysis applied in this paper is straightforward and could be easily integrated to ongoing accessibility measurement and reporting efforts. The existing accessibility data for state and regional geographies should be evaluated using a similar worker-demographic-disaggregation approach to highlight where inequities are most and least prevalent in terms of access to jobs by driving and transit. The national and local trends from such work could guide transportation planners and policy makers on project prioritization-particularly when it comes to promoting equitable mobility and economic opportunity for resident workers. 


\section{References}

El-Geneidy, A., R. Buliung, E. Diab, D. van Lierop, M. Langlois, and A. Legrain. 2016a. Non-stop equity: Assessing daily intersections between transit accessibility and social disparity across the Greater Toronto and Hamilton Area (GTHA). Environment and Planning B: Planning and Design, 43(3):540-560. ISSN 14723417. doi: 10.1177/0265813515617659.

El-Geneidy, A., D. Levinson, E. Diab, G. Boisjoly, D. Verbich, and C. Loong. 2016b. The cost of equity: Assessing transit accessibility and social disparity using total travel cost. Transportation Research Part $A$, 91:302-316. ISSN 0965-8564. doi: 10.1016/j.tra.2016.07.003. URL http://dx. doi.org/10.1016/j.tra.2016.07.003.

Fan, Y., A. Guthrie, and D. Levinson. 2012. Impact of light-rail implementation on labor market accessibility: A transportation equity perspective. Journal of Transport and Land Use, 5(3):28-39. ISSN 19387849. doi: 10.5198/jtlu.v5i3.240.

Foth, N., K. Manaugh, and A. M. El-Geneidy. 2013. Towards equitable transit: Examining transit accessibility and social need in Toronto, Canada, 1996-2006. Journal of Transport Geography, 29:110. ISSN 09666923. doi: 10.1016/j.jtrangeo.2012.12.008.

Gobillon, L., H. Selod, and Y. Zenou. 2007. The Mechanisms of Spatial Mismatch. Urban Studies, 44(12):2401-2427. doi: 10.1080/00420980701540937.

Grengs, J. 2010. Job accessibility and the modal mismatch in Detroit. Journal of Transport Geography, 18:42-54. ISSN 09666923. doi: 10.1016/j.jtrangeo.2009.01.012.

Grengs, J. 2012. Equity and the Social Distribution of Job Accessibility in Detroit. Environment and Planning B: Planning and Design, 39(5):785-800. doi: 10.1068/b36097.

Horner, M. W. 2004. Spatial dimensions of urban commuting: A review of major issues and their implciations. The Professional Geographer, 56(2):160-173.

Kain, J. F. 1968. The Spatial Mismatch Hypothesis: Three Decades Later. Housing Policy Debate, 3(2):371-392.

Kawabata, M. 2003. Job access and employment among low-skilled autoless workers in US metropolitan areas. Environment and Planning A, 35:1651-1668. doi: 10.1068/a35209.

Lee, R. J. and I. N. Sener. 2016. Transportation planning and quality of life: Where do they intersect? Transport Policy, 48:146-155. ISSN 1879310X. doi: 10.1016/j.tranpol.2016.03.004.

Lucas, K., G. Mattioli, and A. Guzman. 2016. Transport poverty and its adverse social consequences. Transport, 169(TR6):353-365. doi: 10.1680/jtran.15.00073. URL http://dx.doi.org/10.1680/ jtran.15.00073.

Owen, A. and B. Murphy. 2018a. Access Across America: Auto 2017. Technical Report CTS 18-16, University of Minnesota, Minneapolis, Minnesota.

Owen, A. and B. Murphy. 2018b. Access Across America: Auto 2017 Methodology. Technical Report CTS 18-17, University of Minnesota, Minneapolis, Minnesota.

Owen, A. and B. Murphy. 2018c. Access Across America: Transit 2017. Technical report, University of Minnesota, Minneapolis, Minnesota.

Owen, A. and B. Murphy. 2018d. Access Across America: Transit 2017 Methodology. Technical Report CTS 18-13, University of Minnesota, Minneapolis, Minnesota.

Pyrialakou, V. D., K. Gkritza, and J. D. Fricker. 2016. Accessibility, mobility, and realized travel behavior: Assessing transport disadvantage from a policy perspective. Journal of Transport Geography, 51:252-269. ISSN 09666923. doi: 10.1016/j.jtrangeo.2016.02.001.

Schneider, I. E., T. Guo, and S. Schroeder. 2013. Quality of Life: Assessment for Transportation Performance Measures. Technical report, University of Minnesota, Minneapolis, Minnesota. URL http://www.lrrb.org/pdf/201305.pdf. 